\title{
Pregnant and Newborn Health in COVID-19 Pandemic: Knowledge level, Attitude and Perspective of Obstetricians \& Gynecologists and Pediatricians in Turkey (A Survey-based Study)
}

\author{
Irem Senyuva ${ }^{1 \star}$, Bora Baysal ${ }^{2}$
}

\begin{abstract}
${ }^{1}$ Usak Training and Research Hospital-Department of Obstetrics and Gynecology, TURKEY
${ }^{2}$ Usak University Medical Faculty- Department of Child Disease, TURKEY

*Corresponding Author: iremsenyuva@yahoo.com
\end{abstract}

Citation: Senyuva I, Baysal B. Pregnant and Newborn Health in COVID-19 Pandemic: Knowledge level, Attitude and Perspective of Obstetricians \& Gynecologists and Pediatricians in Turkey (A Survey-based Study). Electron J Gen Med. 2021;18(3):em287. https://doi.org/10.29333/ejgm/10831

\section{ARTICLE INFO}

Received: 26 Jan. 2021

Accepted: 14 Mar. 2021

\begin{abstract}
Objective: The COVID-19 is a rapidly ongoing pandemic. 368.513 cases and 10.027 fatalities have been reported in Turkey up to this day. Pregnant women and newborns constitute a special patient group in this disease. In our study, we aimed to measure the knowledge level, attitude to protective measures, perspective of education and medicolegal issues of obstetricians - gynecologists (OB-GYN) and pediatricians on pregnant and newborn health about COVID-19.
\end{abstract}

Material-Methods: A cross-sectional, online-survey consisted of 22 questions. Age, academic degree, duration of the profession in the first three questions, level of knowledge about COVID-19 in the next 14 questions, attitude to protective measures, perspective of education and medicolegal issues in the last five questions were queried.

Results: The questionnaire was applied to 145 physicians. $65.5 \%$ of them were pediatricians, $34.4 \%$ were OB-GYN. The level of having adequate knowledge about COVID-19 was determined as $44 \%$ and $34.7 \%$ for OB-GYN and pediatricians. No statistically significant relationship was found between the way of acquiring knowledge and academic degree in both physician groups $(\mathrm{p}>0.05)$.

Positive attitude of OB-GYN about preventive measures during - after the pandemic were $94 \%$ - $90 \%, 96.8 \%$ - $92.6 \%$ for pediatricians. The positive perspective of education and medicolegal measures were determined $72 \%$ and 80 $\%$ for OB-GYN, $80 \%$ and $94.7 \%$ for pediatricians.

Conclusion: Current education related to clinic approach- treatment algoritms about COVID-19 on pregnant and newborn health should be increased for OB-GYN and pediatricians, legal arrangements should be made to make them feel safe.

Keywords: Coronavirus infection, gynecology, obstetrics, pediatrics, survey

\section{INTRODUCTION}

The novel coronavirus ( $\mathrm{n} \mathrm{CoV}$ ) is a single-stranded, nonsegmented, enveloped RNA virus from the beta coronavirus family. It was first detected in Wuhan, China in December 2019, and the disease that it caused in humans was defined as coronavirus disease-2019 (COVID-19) [1]. It has been found that this virus is $85 \%$ similar to Severe Acut Respiratory Stress (SARS)-like CoV found in bats, $79 \%$ to SARS-CoV, which has caused epidemics in the past, and $50 \%$ to Middle East respiratory disease (MERS)-CoV [2]. The World Health Organization (WHO) declared COVID-19 as a national emergency on January 30 and a pandemic on March 12 [1]. According to current data, 43.540 .739 cases and 1.160.650 fatalities have been reported globally as of 28 October, with 368.513 cases and 10.027 fatalities in our country [3].

The review of outbreaks caused by a coronavirus in the world in the last 20 years reveals that the fatality in pregnant women was $25 \%$ in SARS-CoV in 2003, and $23 \%$ in MERS-CoV observed in 2013 [4]. According to the WHO, the SARS mortality rate is $1 \%$ if age $\leq 24$ [5]. Therefore, pregnant and neonatal groups constitute an important place in society in terms of diagnosis, treatment, and follow-up [6]. Current guidelines recommend a multidisciplinary approach involving pediatricians and related branches in addition to an obstetrician in approaching pregnant women with or suspected diagnosis of COVID-19 [4,6,7].

In the current literature, there are a limited number of studies on maternal-fetal and neonatal effects of CoV [8]. The number of losses in the pediatric age group worldwide has been reported to be very low and mostly in the early stages of life [3]. In pregnancy, the effects of COVID-19 in the first two trimesters are not known [9]. Not enough information is available about the vertical transition [8]. Available data show that COVID-19 may lead to negative consequences such as pneumonia in pregnant women, poor pregnancy outcomes, increase cesarean rates, low birth weight, and perinatal death in neonates $[8,9]$. 
The fact that this disease is very recent in the world and healthcare professionals do not have detailed information about this disease may cause the disease to spread rapidly as a result of late diagnosis-treatment $[1,10]$. Therefore, it is important to know the level of knowledge of healthcare professionals about COVID-19, their approach to these patients, and where they are in terms of medical practices [11]. On the other hand, since it is a new disease, ongoing research is rapidly changing the applied treatment algorithms, bringing along problems such as informed consent and medical malpractice $[12,13]$.

In our study, we aimed to measure the knowledge level of OB-GYN and pediatricians about COVID-19 in the pregnant and neonatal patient group and attitude to protective measures, perspective of education and medicolegal issues.

\section{MATERIALS AND METHODS}

This cross-sectional, descriptive online-survey study was conducted in July 2020, which is the fourth month of the epidemic as of March, when the first case was seen in our country. The survey questions were prepared with the help of OB-GYN and pediatrician taking into account the Turkish Ministry of Health COVID-19 and Turkish Neonatal Society guidelines [3,7]. The survey questions were sent online to OBGYN and pediatricians (total of 606 physicians) serving in public, private, state, and university hospitals in Turkey. 145 physicians who completed the survey were included in the study. All participants answered the questions at once. The response time was set at five minutes.

The survey consisted of a total of 22 questions. Age, academic degree, and duration of the profession were investigated in the first three questions of the questionnaire, the level of knowledge about the clinic and treatment of COVID19 in the next 14 questions, attitude to protective measures, perspective of education and medicolegal issues in the last five questions. The questions were open-ended and designed to be answered as yes or no.

Informed consent was considered given upon completion of the survey. The principles of the Declaration of Helsinki were followed in carrying out the present study. This study was approved by the Turkish Ministry of Health under number 202005-08T16_17_54 and decision number 25.10.19 by the Ethics Board of Usak University Faculty of Medicine on 01.07.2020.

Sample numbers were calculated by this formula:

$$
n=\frac{t^{2} p q}{d^{2}}
$$

Table 1. Demographic of OB-GYN and Pediatricians

\begin{tabular}{ccc}
\hline Demographics (n=145) & $\begin{array}{c}\text { OB-GYN } \\
\mathbf{n = 5 0}(\%)\end{array}$ & $\begin{array}{c}\text { Pediatricians } \\
\mathbf{n = 9 5}(\%)\end{array}$ \\
\hline Academic degree & & \\
Academician & $5(10)$ & $70(73,6)$ \\
Minor specialist & $5(10)$ & $16(16,8)$ \\
Specialist Physician & $28(56)$ & $5(5,3)$ \\
Research Assistant & $12(24)$ & $4(4,2)$ \\
\hline Duration of Profession (years) & & \\
$0-5$ & $13(26)$ & $20(21,1)$ \\
$5,1-10$ & $4(8)$ & $25(26,3)$ \\
$10,1-15$ & $6(12)$ & $18(18,9)$ \\
$15,1-20$ & $5(10)$ & $16(16,8)$ \\
$>20,1$ & $22(44)$ & $16(16,8)$ \\
\hline
\end{tabular}

OB-GYN: Obstetricians -Gynecologist

$\mathrm{n}$ : Number of patients to be sampled, t: The theoretical value found according to the $t$ table at a certain level of significance, p: Frequency of appearance of the event under consideration, q: Frequency of occurrence of the event examined, d: Sampling error accepted according to the incidence of the event.

$$
n=\frac{1,96^{2} *(0,5 * 0,5)}{0,08^{2}}=146
$$

$\mathrm{t}$-value for $95 \%$ Confidence Interval $\mathrm{t}=1.96, \mathrm{p}=0.5$, accepted sampling error; $d=0.08$ and calculated sample number was found as 146 .

Statistical analysis was performed with SPSS25. Descriptive analyses were given as percentages and frequency. Chi-Square analysis was used in the relationship between variables. A p of $<0.05$ was considered significant. Power analysis of this study effect size: 0.50 , alfa error: 0.05 , power 0,80 , allocation ratio N2/N1: 2 was calculated and as a result of this group 1: 48 and group 2: 96 , total sample size 144 and actual power: 0.80 was determined.

\section{RESULTS}

A total of 145 physicians completed the survey. Of the participants, 50 (34.4\%) were OB-GYN, 95 (65.5\%) were pediatricians. The average age was $42.26 \pm 10.61(25-66)$ in OBGYN and $40 \pm 8.26$ (25-64) in pediatricians. The professional years and academic degrees of the participants were shown in Table 1.

Knowledge level about COVID-19; Table 2 and Table 3 have shown the levels of information about COVID-19 of OB-GYN and pediatricians.

Table 2. Knowledge levels of OB-GYN about COVID-19 in pregnancy

\begin{tabular}{lc}
\hline Questions & Answers \\
\hline What are the symptoms of COVID-19 disease in pregnant women? & $2(4)$ \\
Fever, cough, dyspnea & $1(2)$ \\
Nausea-vomiting & $1(2)$ \\
Neurological (loss of smell-taste, headache, etc.) & - \\
Skin rash & - \\
Findings related to thromboembolism & $3(6)$ \\
Asymptomatic & $43(86)$ \\
All
\end{tabular}

KFT: Kidney Function Test

LFT: Liver Function Test

Lung CT: Lung Computed Tomography

OB-GYN: Obstetricians -Gynecologist

Pa02: Partial pressure of oxygen 
Table 2 (continued). Knowledge levels of OB-GYN about COVID-19 in pregnancy

\section{Questions}

Which of the following shows that the disease is becoming severe?

Respiration rate per minute $>30$

$\mathrm{Pa02}$ saturation $<95$

Deterioration coagulation profile, LFT, KFT

All

I don't know

Should lung CT be taken in pregnant women?

In all cases

Only in moderate-severe cases

Not recommended

I don't know

Should steroids be administered in a pregnant woman with COVID-19 in a situation where there is the risk of preterm labor at 23 34 weeks or in which pregnancy should be terminated?

Yes

$\mathrm{No} /$

I don't know

Which is true about COVID-19 and pregnancy?

Pregnancy does not worsen the disease, Transmission from mother to infant has not been reported.

It may cause poor pregnancy outcomes. Pregnant women should have detailed anomaly scanning and strict obstetric follow-up. I don't know

According to current guidelines, I have enough information about pregnancy categories and treatment schemes of medications used in the treatment of pregnant women with COVID-19 disease, and emergency obstetric approach algorithms to write the necessary response when a consultation is requested from me.

Yes

No

I have partial knowledge

KFT: Kidney Function Test

LFT: Liver Function Test

Lung CT: Lung Computed Tomography

OB-GYN: Obstetricians -Gynecologist

Pa02: Partial pressure of oxygen

Table 3. OB-GYN and Pediatricians attitude to preventive measures, perspective of education and medicolegal issues on COVID19 during pregnancy and the newborn period

\begin{tabular}{|c|c|c|}
\hline Questions & $\begin{array}{l}\text { OB-GYN } \\
\text { n (\%) }\end{array}$ & $\begin{array}{l}\text { Pediatricians } \\
\text { n (\%) }\end{array}$ \\
\hline \multicolumn{3}{|c|}{$\begin{array}{l}\text { I advise my pregnant patients/their families to wear masks, obey the social distance rule, wash their hands, and apply } \\
\text { to the hospital for symptoms such as sever and cough that they or their infants may be having. }\end{array}$} \\
\hline Yes & $47(94)$ & $92(96.8)$ \\
\hline Sometimes & $1(2)$ & $3(3.2)$ \\
\hline No & $2(4)$ & - \\
\hline \multicolumn{3}{|c|}{$\begin{array}{l}\text { Even if the pandemic is brought under control, I will continue to work with PPE and tell my pregnant patients/patients' } \\
\text { families to continue taking preventive measures until the pandemic is completely over. }\end{array}$} \\
\hline Yes & $45(90)$ & $88(92.6)$ \\
\hline No & $1(2)$ & - \\
\hline I do not know & $4(8)$ & $7(7.4)$ \\
\hline \multicolumn{3}{|c|}{ I learn about COVID-19 related to pregnancy/newborn period as follows: } \\
\hline Academic publication & $39(78)$ & $71(74.7)$ \\
\hline Written or visual media & $3(6)$ & $1(1)$ \\
\hline Non-profit association, foundation, etc. & $6(12)$ & $15(15.7)$ \\
\hline Commercial websites & - & - \\
\hline Social media & - & - \\
\hline Video and podcast sites & - & $1(1)$ \\
\hline Hospital seminars & $2(4)$ & - \\
\hline \multicolumn{3}{|c|}{$\begin{array}{l}\text { I would like to receive a comprehensive training on diagnosis, treatment, patient follow-up, emergency approach etc. } \\
\text { related to COVID-19 and pregnancy/newborn. }\end{array}$} \\
\hline Yes & $36(72)$ & $76(80)$ \\
\hline No & $6(12)$ & $12(12.6)$ \\
\hline I am not sure & $8(16)$ & $7(7.4)$ \\
\hline
\end{tabular}

Answers

$40(80)$

$3(6)$

$2(4)$

37 (74)

$31(62)$

14 (28)

(1)


Table 3 (continued). OB-GYN and Pediatricians attitude to preventive measures, perspective of education and medicolegal issues on COVID-19 during pregnancy and the newborn period

\begin{tabular}{|c|c|c|}
\hline Questions & $\begin{array}{c}\text { OB-GYN } \\
\text { n (\%) }\end{array}$ & $\begin{array}{c}\text { Pediatricians } \\
\mathbf{n}(\%)\end{array}$ \\
\hline \multicolumn{3}{|c|}{ I am concerned that I will have legal problems in the future in maternal - fetal/newborn related issues that may be } \\
\hline \multicolumn{3}{|c|}{ and measures protecting physicians to be taken. } \\
\hline Yes & $40(80)$ & $90(94.7)$ \\
\hline No & $5(10)$ & $1(1.1)$ \\
\hline No idea & $5(10)$ & $4(4.2)$ \\
\hline
\end{tabular}

PPE: Personal Protective Equipment

\section{Knowledge Levels of OB-GYN on COVID-19}

Regarding the symptoms of the disease, 43 (86\%) stated that there may be fever, cough, dyspnea, nausea-vomiting, neurological findings, skin rash, thromboembolic findings or the patients may be asymptomatic, $41(82 \%)$ stated that a respiratory rate of $>30$ per minute, Partial pressure of oxygen (Pa02) saturation of $<95$, deterioration in coagulation profile, Kidney Function Test (KFT) and Liver Function Test (LFT) indicate that the condition is becoming severe, 40 (80\%) stated that the lung Computed Tomography (CT) should be performed in moderate-severe pneumonia cases, 37 (74\%) stated that steroid treatment can be applied in the case of preterm birth/termination, 31 (62\%) stated that pregnancy did not worsen the disease and that vertical transition was not reported, $22(44 \%)$ stated that they have sufficient knowledge about the treatment of and approach to COVID-19.

\section{Knowledge Levels of Pediatricians on COVID-19}

$92(96.8 \%)$ of them stated that there may be all findings concerning the symptoms of the disease such as fever, cough, tachypnea, nausea, and vomiting, 49 (51.5\%) stated that the disease can pass from the mother to the baby only by droplets, $81(85.2 \%)$ stated that findings such as the respiratory rate per minute higher than normal for the age group, respiratory distress, decreased nutrition, and dehydration all indicate the severity of the disease, $84(88.4 \%)$ stated that antenatal steroid treatment could be applied due to preterm labor, 74 (77.9\%) stated that they know the definition of suspected newborns with COVID-19, 81 (85.3\%) stated that suspected asymptomatic infants should be monitored in an isolated room with negative pressure, separate from other infants, 75\% (64.8\%) stated that the mother can breastfeed the infant/give expressed milk with preventive measures, $33(34.7 \%)$ stated that they have sufficient knowledge about the treatment of and approach to COVID-19.

\section{Attitude and Perspective related to COVID-19}

The attitude of OB-GYN about masks, social distance, their compliance with and warning pregnant women about hygiene rules during and after the pandemic were $47(94 \%)$ and 45 (90\%), respectively. It was determined that 39 (78\%) OB-GYN acquired information about COVID-19 from academic publications, and $36(72 \%)$ wanted to receive comprehensive training on COVID-19. It was found out that 40 of them (80\%) had medicolegal concerns during the pandemic period.

The attitude of pediatricians about masks, social distance, their compliance with and warning pregnant women about hygiene rules during and after the pandemic were $92(96.8 \%)$ and $88(92.6 \%)$, respectively.

It was determined that $71(74.7 \%)$ pediatricians acquired information about COVID-19 from academic publications, and $76(80 \%)$ wanted to receive comprehensive training on COVID19. It was found out that 90 of them (94.7\%) had medicolegal concerns during the pandemic period.

There was no statistically significant relationship between the way of acquiring knowledge and academic grade in OB-GYN and pediatricians $(\mathrm{p}=0.821, \mathrm{p}=0.769)$.

The Attitude and Perspective related to COVID-19 of OBGYN and pediatricians were shown in Table 4.

Table 4. Knowledge levels of pediatricians about COVID-19 in the neonatal period

\begin{tabular}{|c|c|}
\hline Questions & $\begin{array}{c}\text { Answers n } \\
(\%)\end{array}$ \\
\hline \multicolumn{2}{|l|}{ How does the mother-to-infant transmission of COVID-19 occur? } \\
\hline Vertical transmission & $10(10.5)$ \\
\hline By droplets & $49(51.5)$ \\
\hline By contact with maternal urine and stool & $1(1)$ \\
\hline All & $30(31.5)$ \\
\hline Transmission is not possible & $2(2.1)$ \\
\hline I have no idea & $3(3.1)$ \\
\hline \multicolumn{2}{|l|}{ What are the symptoms of COVID-19 disease in the neonatal period? } \\
\hline Fever & - \\
\hline Cough & (1) \\
\hline Tachypnea & $1(1)$ \\
\hline Nausea and vomiting & 50 \\
\hline All & $92(96.8)$ \\
\hline I have no idea & $2(2.1)$ \\
\hline \multicolumn{2}{|l|}{ Which indicates that the disease is becoming severe? } \\
\hline The respiratory rate per minute is higher than normal for the age group & $5(5.2)$ \\
\hline Respiratory distress & $7(7.3)$ \\
\hline Decrease in nutrition & $1(1)$ \\
\hline Dehydration & $1(1)$ \\
\hline All & $81(85.2)$ \\
\hline
\end{tabular}


Table 4 (continued). Knowledge levels of pediatricians about COVID-19 in the neonatal period

Questions

Yes

No

Answers $n$

(\%)

have no idea

What does a newborn with suspected COVID-19 mean?

Infant of mother who had COVID-19 infection within 14 days before birth

What is the appropriate approach in an infant with suspected COVID-19?

Contact isolation should be provided until 2 PCR test results taken every 24 hours are negative.

Suspected asymptomatic infants should be monitored in an isolated room with negative pressure, separate from other infants. 81 (85.3)

Contact isolation is not required if there are no symptoms

None

Which is true about breastfeeding in a mother with COVID 19?

Breastfeeding is not recommended for the mother

Breast milk should be used if it comes negative after a PCR test performed

I have no idea

According to current guidelines, I have enough information about the treatment schemes and approach algorithms of medications used in the treatment of newborns with COVID-19 disease.

Yes

I have partial knowledge

Table 5. The relationship between academic degrees and the style of acquiring knowledge in OB-GYN

\begin{tabular}{|c|c|c|c|c|c|c|}
\hline \multicolumn{2}{|c|}{$\begin{array}{c}\text { Academic degree } \\
n(\%)\end{array}$} & \multirow{2}{*}{$\begin{array}{c}\text { Academic } \\
\text { Publication } \\
\text { n (\%) } \\
4(80)\end{array}$} & \multirow{2}{*}{$\begin{array}{c}\text { Hospital } \\
\text { Seminer } \\
\mathbf{n}(\%) \\
0(0)\end{array}$} & \multirow{2}{*}{$\begin{array}{c}\text { Non-Profit Organization, } \\
\text { Written/Visual Media } \\
\mathbf{n}(\%)\end{array}$} & \multirow{2}{*}{$\begin{array}{c}\begin{array}{c}\text { Video/Podcats } \\
\mathbf{n}(\%)\end{array} \\
1(20)\end{array}$} & \multirow{3}{*}{$\mathbf{P}$} \\
\hline Academician & $5(10)$ & & & & & \\
\hline Minor specialist & $5(10)$ & $4(80)$ & $0(0)$ & $0(0)$ & $1(20)$ & \\
\hline Specialist & $28(56)$ & $22(78,5)$ & $1(3,5)$ & $4(14,2)$ & $1(3,5)$ & \multirow{2}{*}{0.821} \\
\hline Asistant & $12(24)$ & $8(66,6)$ & $1(8,3)$ & $2(16,6)$ & $1(8,3)$ & \\
\hline
\end{tabular}

Table 6. The relationship between academic degrees and the style of acquiring knowledge in pediatricians

\begin{tabular}{|c|c|c|c|c|c|c|}
\hline \multicolumn{2}{|c|}{$\begin{array}{c}\text { Academic degree } \\
\mathbf{n}(\%)\end{array}$} & \multirow{2}{*}{$\begin{array}{c}\begin{array}{c}\text { Academic } \\
\text { Publication } \\
\text { n (\%) }\end{array} \\
57(81,4) \\
\end{array}$} & \multirow{2}{*}{$\begin{array}{c}\text { Hospital } \\
\text { Seminer } \\
\mathbf{n}(\%) \\
0(0) \\
\end{array}$} & \multirow{2}{*}{$\begin{array}{c}\begin{array}{c}\text { Non-Profit Organization, } \\
\text { Written/Visual Media } \\
\mathbf{n}(\%)\end{array} \\
11(15,7) \\
\end{array}$} & \multirow{2}{*}{$\begin{array}{c}\begin{array}{c}\text { Video/Podcats } \\
\mathbf{n}(\%)\end{array} \\
1(1,4) \\
\end{array}$} & \multirow{3}{*}{$\mathbf{P}$} \\
\hline Academician & $70(73,6)$ & & & & & \\
\hline Minor specialist & $16(16,8)$ & $12(75)$ & $0(0)$ & $4(25)$ & $0(0)$ & \\
\hline Specialist & $5(5,3)$ & $5(100)$ & $0(0)$ & $0(0)$ & $0(0)$ & \multirow{2}{*}{0.769} \\
\hline Asistant & $4(4,2)$ & $4(100)$ & $0(0)$ & $0(0)$ & $0(0)$ & \\
\hline
\end{tabular}

The relationship between physician groups and the style of acquiring knowledge were shown in Table 5 and Table 6.

\section{DISCUSSION}

In our study, it was determined that both groups of physicians follow the literature regardless of their academic degree, and their level of knowledge about the symptoms and clinical course of COVID-19 is high, but they do not consider themselves sufficient in terms of the clinical approach to the disease and treatment algorithms. It was determined that their attitude to protective measures and perspective of education were high, but they wanted to be protected from medicolegal issues that may arise during this period.
The coronavirus is transmitted to humans through droplets or contact of contaminated surfaces with mucous membranes [5]. Clinical findings of the disease are fever, cough, myalgia, headache, diarrhea, neurological findings in some cases, rash, and thrombosis [14-17]. In general, the disease has a mild course, with $14 \%$ of patients requiring hospitalization and oxygen support, and $5 \%$ intensive care and mortality is $2 \%$ $[4,14]$. COVID-19 has a mild course in infected infants $<1$ year of age [18]. Findings in the newborn include fever, tachypnea, tachycardia, respiratory distress, vomiting-diarrhea, and lethargy [7]. Chest contraction, apnea, malnutrition, moaning, and cyanosis are the worse clinic findings in newborn [3]. In our study, the knowledge level of both physician groups about the symptoms and course of the disease was found to be similar to the information in the literature. 
Studies on the clinical course of COVID-19 in pregnant women in the literature, Matar et al, in their review of 136 pregnant women with COVID-19, found maternal death due to ARDS in only one case and absence of poor outcomes with the immunological adaptation mechanisms during pregnancy [19]. Similarly, Oncel et al. reported that the clinic of COVID-19 in pregnant women was like the normal population and mortality was low, Kasraeian et al. found no significant difference in severe disease, intensive care and mortality rates in pregnant women $(p=0.1, p=0.474, p=0.998)[8,20]$. The level of knowledge of OB-GYN group in our study about the clinical course of COVID-19 in pregnant women was found to be similar to the literature.

Angiotensin-converting enzyme 2 (ACE 2) receptors are found in the placenta, trophoblast, endothelium, and villi, so there may be a vertical transmission [21]. Also, endothelial damage has been shown in the placenta vessels of mothers with COVID-19, and it has been stated that it may lead to conditions such as preeclampsia, premature birth, and growth retardation [21]. In line with this information, Kasraeian et al. found the rates of cesarean section, prematurity, fetal distress, and premature rupture of membranes in 87 pregnant women with COVID-19 as $92 \%, 60 \%, 30 \%$ and $14 \%$, respectively, and they did not report vertical transmission [20]. In a different study, Melo et al. did not find a significant relationship between preterm birth and birth weight and the disease in 60 pregnant women with COVID-19 ( $p>0.05$ ) [22]. Matar et al. found a $37 \%$ preterm birth and a $76 \%$ cesarean rate in 136 pregnant women with COVID-19 [19]. Di Mascio et al. found pre-term delivery, premature rupture of membranes, cesarean, perinatal death, fetal distress, and preeclampsia in pregnant women with COVID-19 as $41.1 \%, 18.8 \%, 91 \%, 7 \%, 43 \%$ and $14.6 \%$, respectively, but did not report vertical transmission [9]. Differently, Oncel et al. investigated 125 pregnant women with COVID-19 in March-June and found the rates of cesarean section, prematurity, and low birth weight as $71.2 \%, 26.4 \%$ and $12.8 \%$, respectively, and reported Polymerase Chain Reaction (PCR) positivity at a rate of $3.3 \%$ in newborns [8]. Vivanti et al. virologically and pathologically showed coronavirus transmission in the placenta [23]. Similarly, Koltyar et al. examined 936 newborns with COVID-19 disease, in nasopharyngeal swab, cord blood, placenta, amniotic fluid, urine and fecal swab samples, they detected 3.2\% (95\% Cl 2.24.3\%), $2.9 \%, 7.7 \%, 0 \%$ and $9.7 \%$ and found a rate of $3.7 \%$ for neonatal coronavirus immunoglobulin $\mathrm{M}$ (IgM). Since Ig $\mathrm{M}$ occurs in the acute period and cannot pass through the placenta, they evaluated its detection in the newborn in favor of infection [21]. All the information in this literature shows that vertical transition cannot be excluded clearly. In our study, the knowledge levels of study groups about poor pregnancy outcomes and vertical transition were found low. It may be a factor that there were more review articles on vertical transition published in newly July or lack of clarity on this issue in literature.

The gold standard method in the diagnosis of COVID-19 disease is the Revers-Transcriptase PCR (RT-PCR) test with a specificity of $91 \%$ and a sensitivity of $95-97 \%$ [18]. In the diagnosis of lung involvement, the "ground-glass" image on lung CT is typical and is seen in $56.4 \%$ of patients $[4,24]$.

In the practice in pregnant women, the Ministry of Health stated that lung $\mathrm{CT}$ is not a definite contraindication and that it can be administered with low doses by protecting the fetus [3].
In our study, the knowledge of OB-GYN group is similar to the literature.

Clinical approach to pregnant women with COVID-19 should be routine in uncomplicated cases and planned and multidisciplinary in high-risk pregnancies [6]. In emergency labor, the method of delivery should be decided according to the clinical findings of the patient, and oxygen saturation should be $>95 \%$ in intrapartum follow-up, and in cases that become severe in vaginal delivery, cesarean section, or shortening of the second phase of delivery should be considered [4]. COVID-19 is not a cesarean indication [4,9,25]. There is no superiority of early or late cord clamp $[5,26]$. Medical treatment options in pregnant women are immunomodulators, antiviral therapy, convalescent plasma and thromboprophylaxis based on expert opinion $[3,27,28]$. OB-GYN physicians in our study evaluated their level of knowledge about clinical approach and treatment algorithms on COVID-19 during pregnancy as insufficient.

Concerning steroid administration, the American College of Obstetricians and Gynecologists (ACOG), the Turkish MaternalFetal Medicine Perinatology Association (TMFT) stated that steroids should be given by a multidisciplinary team and not contraindicated for COVID-19 $[4,24,25,29]$. Currently, steroids are recommended in severe COVID-19 and ARDS cases (24). Both physician groups in our study have similar information with the literature about steroid administration.

A newborn with suspected COVID-19 is defined as a neonate born from a mother with COVID-19 disease 14 days before the birth-postnatal 28-day period and if the family and relatives have COVID-19 disease. The neonate is definitely infected if there is COVID-19 PCR positivity in respiratory and blood samples of the newborn [7]. Isolation and hygiene rules, early clamping of the cord, taking multiple swabs from the newborn and repeating it 24 hours later, and a multidisciplinary approach in treatment are recommended in the approach to the newborn with COVID-19 [7]. Supportive treatment, avoiding unnecessary broad-spectrum antibiotics, surfactants, inhaled nitrite oxide, and high-frequency ventilation can be used in severe ARDS cases in medical treatment $[7,30]$.

The pediatricians in our study evaluated their level of knowledge about clinical approach and treatment algorithms about COVID-19 in newborns as insufficient. There were lower pediatrics caseload when compared to adult side may be a factor.

There are conflicting recommendations regarding breastfeeding for mothers with COVID-19. In the studies conducted in the literature, breast milk of mothers with COVID19 was found to be negative $[18,25,31]$. While the WHO and Centers for Disease Control and Prevention (CDC) recommended breast and expressed milk with preventive measures, the Turkish Neonatology Association recommended that breast milk should be given if PCR is found to be negative, and even not be given until a clear consensus is reached $[7,26,31]$. The level of knowledge of pediatricians on this subject is similar to the literature.

Medical mask, 1-1.5 meters of social distance, the rule of 20-second hand washing are important in protection from COVID-19 [3]. In the literature, in the questionnaires applied to healthcare professionals about preventive measures, the perception on this issue has been found to be from low to high 
[10]. In our study, the attitude to preventive measures is high in both physician groups.

In the surveys conducted on COVID-19, it was determined that healthcare professionals obtained information through channels such as the WHO, national health ministry websites, and social media posts $[1,10]$. In our study, unlike the literature, the way both physician groups obtained information was following academic publications.

During the COVID-19 pandemic period, conditions such as difficult clinical conditions, patient safety, consent form, working outside their own field, and increased workload may predispose to medicolegal problems [12]. In addition, it has been determined in clinical studies that surgical intervention performed during the COVID-19 asymptomatic or incubation period will worsen the course of the disease [32]. It has been stated by the Ministry of Health of our country that anesthesia and surgical intervention will negatively affect the course of the disease [3].

The consent form is especially important in medicolegal situations in emergencies, and the patient should be informed that they may be infected with coronavirus in the peri- or postop period during the pandemic and this situation will pose a risk for them in the long-short term [13]. In our study, the medicolegal perspective of both physician groups during the pandemic period was found to be high.

The present study has some limitations; participation rate of healthcare professionals was low. The factors for low questionnaire participation of healthcare professionals were reported as insufficient time, conspicuousness of the subject, confidentiality of the results, prejudiced perception for personal question, length of the questions and personal experience of the participants [33]. We believe that workload of professionals or the problems encountered with the delivery of the questionnaire to the e-mail addresses have led to the low participation ratio. Because of their insufficient knowledge level of some participants may not have answered the questions or may have prefered 'all'option. All of these may be a negative factor survey success.

In conclusion, COVID-19 pandemic and studies thereon are rapidly ongoing, and the current information is constantly being updated. Correct information and approach mean quality health care. For this reason, scientific presentations in which up-to-date information is conveyed about clinical approach-treatment practices in pregnant women and newborns with COVID-19 for OB-GYN and pediatricians should be increased throughout the country. Medicolegal arrangements for protecting physicians to COVID-19 should not only be in the consent forms but also legal amendments in particularly critical and emergency COVID cases.

Author contributions: Senyuva I contributed to the conception, design, data collecting, writing and revision of the manuscript. Baysal B contributed to data collecting.

Funding: This work has no funding.

Declaration of interest: The authors have no conflicts of interest.

Acknowledgements: The authors thanks to Hande Emir for statistica analysis of manuscript also all the participants who completed the survey.

\section{REFERENCES}

1. Bhagavathula AS, Aldhaleei W A, Rahmani J, Malabadi M A, Bandari D K. Knowledge and Perceptions of COVID-19 Among Health Care Workers: Cross-Sectional Study. JMIR Public Health Surveill. 2020;6(2):e19160. https://doi.org/ 10.2196/19160 PMid:32320381 PMCid:PMC7193987

2. Rasmussen SA, Smulian JC, Lednicky JA, Wen TS, Jamieson DJ. Coronavirus Disease 2019 (COVID-19) and pregnancy: what obstetricians need to know. Am J Obstet Gynecol 2020 222(5):415-26. https://doi.org/10.1016/j.ajog.2020. 02.017 PMid:32105680 PMCid:PMC7093856

3. https://COVID19.saglik.gov.tr/ (Accessed: 28 October 2020).

4. https://www.tmftp.org/tr/COVID-19 (Accessed: 3 April 2020).

5. https://www.who.int/csr/sarsarchive/2003_05_07a/en/.Pu blished

6. Dilbaz B. COVID-19 Infection and Pregnancy: What Do the Societies Recommend. J Clin Obstet Gynecol. 2020;30(1):29-34. https://doi.org/10.5336/jcog.2020-75346

7. https://www.neonatology.org.tr (Accessed: 23 March 2020).

8. Oncel MY, Akın IM, Kanburoglu MK et al. A multicenter study on epidemiological and clinical characteristics of 125 newborns born to women infected with COVID-19 by Turkish Neonatal Society. Eur J Pediatr. 2020;10:1-10. https://doi.org/10.1007/s00431-020-03767-5 PMid:32776309 PMCid:PMC7416592

9. Di Mascio D, Khalil A, Saccone $G$ et al. Outcome of coronavirus spectrum infections (SARS, MERS, COVID-19) during pregnancy: a systematic review and meta-analysis. Am J Obstet Gynecol MFM. 2020;2(2):100107. https://doi.org/10.1016/j.ajogmf.2020.100107 PMid:32292902 PMCid:PMC7104131

10. Wahed WYA, Hefzy E M, Ahmed MI, Hamed N S. Assessment of Knowledge, Attitudes, and Perception of Health Care Workers Regarding COVID 19, A Cross Sectional Study from Egypt. Community Health. 2020;7:1-10. https://doi.org/ 10.1007/s10900-020-00882-0 PMid:32638199 PMCid: PMC7340762

11. Zhou M, Tang F, Wang Y, et al. Knowledge, attitude and practice regarding COVID-19 among health care workers in Henan, China. J Hosp Infect. 2020;105(2):183-7. https://doi.org/10.1016/j.jhin.2020.04.012 PMid:32278701 PMCid:PMC7194961

12. Vilanilam GC, John PK. Medicolegal challenges in the COVID era. Arch Med Health Sci 2020;8:83-7. https://doi.org/ 10.4103/amhs.amhs_109_20

13. Tripathy S, Mohapatra S. Informed Consent for Emergency Obstetric Care During COVID-19 Pandemic. Obstet Gynaecol India. 2020;70(4):275-8. https://doi.org/10.1007/ s13224-020-01339-z PMid:32760173 PMCid:PMC7333934

14. Thomas B, Pallivalapila A, El Kassem Wet al. Maternal and perinatal outcomes and pharmacological management of COVID-19 infection in pregnancy: a systematic review protocol. Syst Rev. 2020;18(1):161. https://doi.org/10.1186/ s13643-020-01418-2 PMid:32682444 PMCid:PMC7368633

15. Öner Ü, Akdeniz N. COVID-19 ile İlişkili Kutanöz Bulgular. Anadolu Kliniği Tıp Bilimleri Dergisi 2020;25:1. https://doi.org/10.21673/anadoluklin.734567 
16. Singhania N, Bansal S, Nimmatoori DP, Ejaz AA, McCullough PA, Singhania G. Current Overview on Hypercoagulability in COVID-19. Am J Cardiovasc Drugs. 2020;20(5):393-403. https://doi.org/10.1007/s40256-020-00431-z PMid:32748336 PMCid:PMC7398761

17. Singhania N, Bansal S, Singhania G. An Atypical Presentation of Novel Coronavirus Disease 2019 (COVID19). Am J Med. 2020;133(7):e365-e366. https://doi.org/ 10.1016/j.amjmed.2020.03.026 PMid:32320693 PMCid: PMC7167564

18. Mustafa NM, A Selim L. Characterisation of COVID-19 Pandemic in Paediatric Age Group: A Systematic Review and Meta-Analysis. J Clin Virol. 2020;128:104395. https://doi.org/10.1016/j.jcv.2020.104395 PMid:32417675 PMCid:PMC7207144

19. Matar R, Alrahmani L, Monzer $\mathrm{N}$ et al. Clinical Presentation and Outcomes of Pregnant Women with COVID-19: A Systematic Review and Meta-Analysis. Clin Infect Dis. 2020; 23:828. https://doi.org/10.1093/cid/ciaa828 PMid: 32575114 PMCid:PMC7337697

20. Kasraeian M, Zare M, Vafaei H, et al. COVID-19 pneumonia and pregnancy; a systematic review and meta-analysis. J Matern Fetal Neonatal Med. 2020;19:1-8. https://doi.org/ 10.1080/14767058.2020.1763952 PMid:32429786

21. Kotlyar A, Grechukhina O, Chen A et al. Vertical Transmission of COVID-19: A Systematic Review and Metaanalysis. Am J Obstet Gynecol. 2020;31(1):S0002-93 78(20)30823-1. https://doi.org/10.1016/j.ajog.2020.07.049 PMid:32739398 PMCid:PMC7392880

22. Melo GC, Araújo KCGM. COVID-19 infection in pregnant women, preterm delivery, birth weight, and vertical transmission: a systematic review and meta-analysis. Cad Saude Publica. 2020;36(7):00087320. https://doi.org/ 10.1590/0102-311x00087320 PMid:32696830

23. Vivanti AJ, Vauloup-Fellous C, Prevot Set al. Transplacental transmission of SARS-CoV-2 infection. Nat Commun. 2020; 14(1):3572. https://doi.org/10.1038/s41467-020-17436-6 PMid:32665677 PMCid:PMC7360599
24. Edis E Ç, Dikensoy Ö, Köktürk N, Kılınç O, Eyüboğlu F Ö, Özkan M et al. COVID-19 Hastalarında Tanı, Tedavi ve İzlem. Ed: İtil O, Ergür G A, Köktürk N, Havlucu Y, Akgün M. Her Yönüyle COVID-19. First ed. Türkiye. Türk Toraks Derneği.2020:100-5.

25. https://www.acog.org (Accessed: 12 August 2020).

26. https://www.who.int (Accessed: 27 May 2020).

27. D’Souza R, Malhamé I, Teshler L, Acharya G, Hunt BJ, McLintock C. A critical review of the pathophysiology of thrombotic complications and clinical practice recommendations for thromboprophylaxis in pregnant patients with COVID-19. Acta Obstet Gynecol Scand. 2020 2020;00:1-11. https://doi.org/10.1111/aogs.13962 PMid: 32678949 PMCid:PMC7404828

28. Soleimani Z, Soleimani A. ADRS due to COVID-19 in mid term pregnancy: successful management with plasma transfusion and corticosteroids. J Matern Fetal Neonatal Med. 2020;26:1-4. https://doi.org/10.1080/14767058. 2020.1797669 PMid:32715804

29. Akpinar F, Ustun Y. Current information about SARS-COV-2 (COVID-19) infection in obstetrics and gynecology practice. Turk J Womens Health Neonatol 2020;2(1):13-6.

30. Erdeve Ö, Çetinkaya M, et al. The Turkish Neonatal Society proposal for the management of COVID-19 in the neonatal intensive care unit. Turk Pediatri Ars. 2020;55(2): 86-92. https://doi.org/10.14744/TurkPediatriArs.2020.43788

31. https://www.cdc.gov (Accessed: 11 September 2020).

32. Lei S, Jiang F, Su W, et al. Clinical characteristics and outcomes of patients undergoing surgeries during the incubation period of COVID-19 infection. EClinical Medicine. 2020;5:100331. https://doi.org/10.1016/j.eclinm. 2020.100331 PMid:32292899 PMCid:PMC7128617

33. VanGeest JB, Johnson TP, Welch VL. Methodologies for improving response rates in surveys of physicians: a systematic review. Eval Health Prof. 2007;30(4):303-21. https://doi.org/10.1177/0163278707307899 PMid:17986667 